\title{
14. Intervention Logic/ Program Logic: Toward Good Practice
}

\author{
Karen Baehler, School of Government, Victoria University \\ of Wellington
}

\begin{abstract}
Although it is often possible to assess policy separately from service delivery, good final outcomes for citizens invariably depend on smart policies being effectively implemented. It makes sense, therefore, to look for ways of improving performance in both realms - policy and service delivery - simultaneously and collaboratively. A contrivance known as intervention logic or program logic is being recognised in Australasia as one such tool for bridging the policy-implementation divide and thereby contributing to organisational change and renewal. Logic models work by introducing a single framework for designing, managing, and evaluating programs and projects. This chapter will briefly describe that single framework and discuss recent applications of logic modelling in New Zealand's public sector, including lessons learned about good and bad practice in logic modelling.
\end{abstract}

\section{Introduction}

The pursuit of better government is unquestionably a noble pursuit, and one which springs, at least most of the time, from the better angels of our nature to which Abraham Lincoln once referred. Noble intentions do not necessarily guarantee good results, however, and so we find that many bright ideas for improving government processes and operations only barely see the light of day before fading into obscurity. My colleague Bob Gregory (2004) has called the roll of these now-forgotten innovations - zero-based budgeting, management by objectives (MBO), total quality management (TQM), and planning programming and budgeting systems (PPBS), for starters - and reminded us that current and future innovations of the same ilk are likely to suffer the same fate, despite their creators' good intentions.

The analysis presented here begins by acknowledging this important lesson of history, but then looks beyond it to see whether a more stable core of knowledge, insight, and common sense might lie below the surface of fluctuating public management fashions and political tastes for public sector reform. If such a core exists, and if it has the potential to contribute to long-term progress in government performance, then it is worthwhile trying to unearth it. One place to start doing this is with a disparate set of good-practice methods drawn from 
the fields of public policy, program evaluation, and public management, all of which reflect a common set of basic propositions about the nature of policy and policymaking.

This chapter has two main purposes: (1) to identify and describe a common core of common sense wisdom that unites recent developments in the areas of policy design, public management, and program evaluation, and (2) to plead the case for focusing our limited attention on developing, nurturing, and applying this core of ideas across the public sector, rather than perpetuating competition among new policy and management 'innovations' and their acronyms.

\section{The Common Core}

In today's fragmented and narrowly specialised public sector, different functional areas quickly develop their own distinctive language and practice. Thus, as public management theory and practice has settled into the current era of 'managing-for-outcomes' (MfO) and 'results-based management', the field of policy analysis and advice has been striving to become better informed by evidence, sensitive to community concerns and interests, forward-thinking, and outward-looking. Over the same period, program evaluators have been developing a wide array of methodologies suited to different kinds of evaluation tasks, as well as experimenting with and adapting techniques drawn from the fields of systems thinking and dynamics and dabbling in complexity theory, while those in charge of public sector service delivery have been seeking to lift their game by way of project management applications and other methods.

Optimistic outsiders gazing down upon this scene may see a rich abundance of public sector energy and creativity which is bound to generate improvement, but their pessimistic counterparts will be quick to note that continual proliferation of new techniques and methods within narrowly defined areas of public sector activity is more likely to build a bigger and better Tower of Babel than it is to improve actual government performance. With policy, management, evaluation, and service delivery experts all pursuing their own discipline-specific, smart-practice innovations, it is no wonder that practitioners in these fields are finding it hard to talk to each other and work together effectively. Intra- and inter-agency cooperative networks may be all the rage in public sector studies, but scant attention has been paid to the ways in which core, discipline-based practices actually impede such collaboration. Exhorting policy advisers, public managers, evaluators, and service deliverers to spend more time building networks, sharing information, and looking for collaborative opportunities will not yield fruit so long as the professionals in these fields are speaking different languages with respect to good practice.

Fortunately, beneath the buzzword-babble of outcomes, systems, complexity, and evidence, one can detect a common core of plain-language meanings from 
which shared understanding and action may emerge. What unites these various devices and techniques are two simple and familiar, but also revolutionary, ideas about means and ends:

1. policy means and ends, and the theories of cause and effect that connect them, should nearly always be considered together; and

2. where public purposes are concerned, only citizens can complete the process of converting public resources into real outcomes. Government cannot do everything; it constantly relies on the active cooperation of citizens.

New Zealand's embrace of managing-for-outcomes (MfO) was justified partly on the grounds of the first idea. Although the big state sector reforms of the 1980s clearly had accomplished much in the way of efficient delivery of programs and services and transparent governance, some critics concluded that the New Zealand model's strong focus on monitoring and reporting outputs was causing the public service to lose sight of policy objectives (Schick 2001, Steering Group 2002). With ministers officially accountable for outcomes and agency chief executives primarily accountable for outputs (and for reporting on the links between the two), there were concerns that these two essential actors, and their respective institutions, were slowly drifting apart into their own preoccupations.

The common language and shared mission of MfO was therefore needed to reconnect outputs with outcomes and to reconnect government departments with both ministers and the people whom they serve. Central agencies put considerable effort into helping agencies articulate their 'vital few' high-level outcomes in ways that would clarify links as well as gaps between the agency's outputs and intended outcomes, with the ultimate goal of helping agencies rethink and then reconfigure their output mix for greater effectiveness. It is too early to say whether or not MfO has had the desired effect yet. There is always the danger that a focus on outcomes will perpetuate or aggravate the artificial distinction between outputs (means) and outcomes (ends), rather than reconnecting them. Whatever the result, it is worth remembering that restoring the integrity of the output-outcome chain was at least part of the original intention. It is also worth noting that many of MfO's effects on actual departmental practice may be both powerful and unobservable; the fact that evaluations cannot pick up these effects does not mean they are not present.

The idea that means and ends always travel together also has roots in certain perspectives on policy analysis. Whereas the conventional view of public policy assumes that decision makers set policy objectives and analysts/advisers design various configurations of resources (in the form of programs and policies) for reaching those objectives, Aaron Wildavsky (1987) defined a public policy as a yoked phenomenon - a program together with its goals or a particular set of resources tied to particular objectives. We might call it a sort of means-and-ends package deal. In order to ensure the coherence of this package, it is also necessary 
to include some kind of theory, rationale, or causal logic that explains why those particular means are expected to generate those particular ends. For example, the policy of providing welfare benefits is linked to the outcome of improved family well being and social solidarity according to a typical social democratic view of causation, whereas a more conservative worldview links the very same policy to an entirely different set of outcomes that includes inter-generational dependency, declining well being, and resentment between the working poor and the beneficiary poor. Thus, means and ends are not enough to specify a policy; some sort of linking theory or logic is also needed.

Viewed in this way, policy choice becomes not only a choice among alternative programs, services, regulatory schemes, or activities, but also a choice among alternative objectives, the achievement of which would constitute each related program's aim, as well as a choice among causal theories. This redefinition of the policy choice process as a simultaneous and interlocking (rather than sequential or hierarchical) choice of ends, means, and causal theories has significant implications for those who give advice about improving government performance, because if Wildavsky was right, then determining which programs and services are 'best' cannot be done by reference to externally derived policy objectives. Instead, advisers need to present policy options in the form of alternative program packages, each designed to achieve a slightly different configuration of objectives via its own combination of multiple instruments and resources, and each supported by its own causal theory. Advisers also need to present decision makers with information that will help them compare the alternative packages in terms of feasibility, costs, risks, uncertainties, distributional impacts, and, where possible, likely overall effectiveness. Decision makers need to know not only what the program is meant to produce and how it is meant to do so, but also whose cooperation and/or compliance is required to make it work and the kinds of circumstances that are most likely to support or undermine it. This approach to policy advice recognises that policy choices are nearly always driven by a combination of technical, broadly political, and more narrowly partisan considerations. It does so by presenting program options as multi-dimensional packages and recognising that different actors and stakeholder groups inside and outside government will focus on different dimensions of the selected package.

Wildavsky's yoked definition of public policy also has implications for program evaluation. In addition to the familiar problem of attributing specific outcomes to specific actions by government, the desired outcomes themselves are seen as a matter of policy choice and, therefore, subject to interpretation and change over time. Among the various professional groups associated with the public policymaking process, evaluators have been leaders in thinking about how means-ends connections and causal theories should be studied amidst uncertainty and complexity. 
Examples of yoked policy choices are not hard to find. In the area of drug policy, choosing between a policy of stricter sentences for drug convictions or a policy of decriminalisation also constitutes a choice between the objective of clearly communicating society's disapproval of drug-taking behaviour, on one hand, or on the other hand, loosening that message in order to pursue a different objective, that is, reducing the social and financial costs associated with drug law enforcement. In an area such as transport, choices among competing objectives are often much more explicit, as when government must divvy up its limited budget for road works among competing projects with different objectives, such as alleviating big city traffic congestion versus improving market access for rural farmers versus reducing road accidents and fatalities. Virtually all allocative policy choices have this simultaneous ends-means quality about them. This is why very few experts have even attempted to devise technical schemes for solving government's grand budget allocation decisions - guns vs butter or health vs education vs housing. Examples of competing causal theories are also plentiful. The invasion of Iraq was expected by some to liberate the Iraqi people from oppression and ultimately contribute to Middle East stability and development, while others expected it to fuel civil war in Iraq and destabilise the region.

A particular program or policy's intended links between means and ends can, of course, be strong or weak, direct or indirect, proximate or distant; the causal theory may be based on evidence, educated guesses, or flights of fancy. Whatever their features, it is these hypothesised links in the cause-and-effect chain that communicate government's intentions and thereby provide the platform from which policy designers, implementation planners, and operational units can go about their core business of marshalling resources and enabling people inside and outside of government to work together converting resources into desired outcomes.

This brings us to the second core idea signalled earlier. The second unifying theme from recent developments in good practice is that turning outputs into outcomes, or public means into public ends, is fundamentally a process of co-production that requires action by both government and citizens. This principle may seem obvious in cases such as social services, where the effectiveness of social work interventions clearly depends upon the receptiveness and responsiveness of the client. ${ }^{1}$ But even the least touchy-feely of all public functions - national defence - depends upon people paying their taxes, refraining from gratuitous actions that would undermine the military (such as interfering with military exercises or bombing military bases), and keeping a watchful eye on government's use of military power. These sorts of activities, in turn, depend upon public support for the norms of parliamentary representation and oversight, a free press, and free speech, to name just a few of the essential prerequisites to healthy democratic governance. Although some of these citizen obligations are 
backed by laws and the threat of penalties for non-compliance (including voting in Australia and census participation in New Zealand), we assume that the vast majority of people will fulfil their obligations voluntarily. Production of the resulting goods can therefore be attributed in large measure to high levels of cooperation.

Examples of co-production are everywhere. Government determines eligibility for benefits and writes benefit checks, but it is up to individual beneficiaries how they will spend the money to sustain their families. Government builds roads, but citizens decide when and where to drive on them for purposes of work, recreation, socialising, etc. Citizens also choose how fast to drive (with or without regard to posted speed limits) and with what level of care and attention (with or without regard to legal definitions of reckless driving). Government funds universities, but citizens decide whether and what to study, how much effort to expend, and whether to join or resist the brain drain once they graduate. Understanding these co-production processes is central to designing smart policies that will encourage, enable, educate, persuade, bribe, or coerce citizens into making the kinds of choices that contribute most to aggregate public goals.

Although the principle of co-production is not often acknowledged explicitly, it is implicit in current conversations about accountability for outcomes, participatory policy design, and public trust in government. New Zealand central agencies have worked hard over the past several years to reassure chief executives that they are being held accountable for outputs and 'managing for outcomes' only (always in inverted commas), and not for actual outcomes themselves. This sort of approach acknowledges the complex web of factors that combine to determine any social or economic outcome, and recognises that government policy contributes only a few sticky threads to that web. It is a small step from this acknowledgment to embracing a co-production model of the output-outcome chain. Those who agitate for more participatory approaches to policy design, through more and better consultation for example, also seem to tacitly understand the role that citizens play (whether they are consulted or not) in the achievement or undermining of policy goals, although the pro-participation advocates often couch their arguments more in terms of democratic principles than co-production realities. Likewise, those who warn about citizens' declining trust in government clearly understand the central role that citizens play in the work of government even if they do not always acknowledge policy-specific cases of co-production.

Scratching below the surface of current public sector fashions reveals at least two core ideas - the principle of means-ends dependency and inseparability in public policy, and the principle of government-citizen co-production - which may be worthy of further development. A currently popular set of concepts known as program or intervention logic in Australasia (or the results chain in Canada) provides one possible avenue for this development. 


\section{Intervention or Program Logic}

As noted above, the linchpin of a yoked approach to means and ends is the theory of causation. Such a theory consists of assumptions and propositions that lead from a policy, program or service idea - such as an immigration point scheme that favours applicants with certain job skills or a program of tax credits for research and development investments - to a policy goal, such as economic growth. It is very much like an argument, and the causal logic for any particular policy or program should, in fact, reflect the substantive arguments being made in favour of that policy or program in the political arena, while also addressing the substantive arguments being made against it. Causal theories or logics can be presented in many different forms ranging from a simple narrative that describes an expected scenario (textual) to a causal loop diagram (visual) to a decision tree model populated with probabilities of selected events (visual and mathematical).

In Australia and New Zealand, a linear form of presentation known as intervention or program logic has enjoyed some popularity over the last few years. This version of logic modelling is based largely on the work of Sue Funnell (1997), who focused on evaluation applications but also noted the potential for logic modelling to function as an ex ante policy design device, a point also made in the international development literature (Saldanha and Whittle 1998). In their 2002-2004 guidance to departments preparing Statements of Intent, New Zealand central agencies promoted the use of intervention logic as a tool for presenting each department's full array of output-outcome chains, thereby propelling logic modelling into yet another realm of practice, that of organisational strategic planning and public management.

Following Michael Quinn Patton (1997: p. 221), we can describe the logic of a government intervention in terms of a 'theory-of-action,' i.e., a set of assumptions and inferences about cause-and-effect that add up to a theory of 'how to produce a desired result'. Such theories may spring from academic work or they may be found among what Robert Gregory (1989: p. 141) calls the 'inchoate hypotheses' held by virtually all decision makers, or the rough-and-ready assertions by politicians that the future will be brighter if my preferred policies are pursued rather than yours. Douglas Arnold (1990: p. 18) views 'causal chains' as the common currency of citizens, legislators, and coalition leaders within legislatures, and therefore as the heart of policy debate:

A large part of any policy discussion is a debate about cause and effect, and it is so whether the debate occurs on the evening news, in living rooms across America, in the halls of academe, or in the halls of Congress.

Unlike theories in science, policy theories are always normative; they describe the intended sequence of causes and effects associated with an actual or proposed 
policy, rather than the actual sequence. Thus, in order to understand such theories, logic modelling must start optimistically: It consults common sense and asks the policy's supporters how the policy is meant to work, ideally; in other words, it models the intentions rather than actual effects. The optimistic model is then subjected to relentless critical scrutiny.

A policy's intended theory-of-action may be illustrated by a sequence or chain of outcomes, each stage of which represents both an end (i.e., the outcome of the previous link's success) and a means (i.e., a prerequisite for reaching the next link). The particular policy, intervention, or output to be examined fixes the bottom of the chain; the policy's end outcome or chief goal provides the top fixture; and the mechanisms by which the intervention is expected to work form the middle links of the chain. In many cases, a single intervention or output will have more than one ultimate outcome, in which case the chains of outcomes leading to each form a sort of bouquet of logics. In other cases, a single intervention will link to a single end outcome via more than one rationale, in which case the chain of outcomes will sprout branches that rejoin at the top. A variety of configurations is possible.

The chain of outcomes and hypotheses provides a platform for the most important step in the intervention logic exercise: exposing what the policy seems to be taking for granted, that is, its assumptions (Cato et al, 1998). Every policy rests upon assumptions concerning the suitability of its 'technology' to the situation. For example, welfare-to-work programs assume that jobs are available for former beneficiaries; anti-smoking media campaigns assume that people respond in predictable ways to public-service advertisements; tax breaks for targeted industries assume that businesses take taxation into consideration when making location choices; devolution assumes that lower levels of government can absorb new functions effectively. In an intervention logic model, key assumptions will slot in at particular links in the chain.

Revealing assumptions about relevant social, environmental, economic, legal, or behavioural prerequisites to success is the shortest route to unearthing the risks embedded in any given policy proposal. Indeed, risks can be defined as what happens when assumptions go wrong. They are a combination of (1) factors that might derail progress along a chain of outcomes, plus (2) factors that might cause even a successful policy chain to generate unwanted side effects or unintended consequences. A chain of risks associated with a chain of outcomes and assumptions often adds up to an argument against the intervention in question - what might be called the pessimistic or opposition logic. As described later, studying the opposition's arguments against a policy is a highly efficient way to identify some of that policy's risks.

Other horizontal dimensions may be added to the logic model as well, and are described below. 


\section{Factors inside and outside control}

As one moves up a chain of outcomes, the number of variables within government's control tends to diminish while those outside government's control expand (Funnell, 1997). Identifying factors within government's control helps analysts and managers pinpoint where an agency has some leverage over events, while identifying factors outside control exposes complicating factors. Together, these factors begin to define the boundaries for a systems view of the policy in question (Stewart and Ayres, 2001).

\section{Opportunities for collaborating with other agencies either inside or outside of Government}

Factors outside the agency's control may fall within the control of someone else who qualifies as a natural collaborator in the project. If that someone else is another government department or a community organisation, then the author of the logic has good reason to reach out to the specified organisation(s) to discuss possible partnerships or cooperation arrangements. Policy logics provide clear grounds for joined-up initiatives.

If the outside actors with control are the program's clients or just citizens in general, then the co-production element of the program can be seen as emerging, and program designers will want to think carefully about how the program is expected to interface with and potentially influence the behaviour of these key actors.

\section{Enabling outputs}

Managing the risks to a given intervention and keeping the outcomes chain on track may require additional interventions over and above the program being modelled. This step prompts the policy designer/adviser to think about the whole package of instruments and resources that may be needed to help a policy idea achieve its associated objectives.

\section{Target outcomes (intermediate and final) versus 'actuals'}

Funnell's (1997) approach expands from an output-outcome backbone to a management and evaluation matrix where resources can be allocated to various stages of the logic, the program's progress can be monitored at each stage of the intermediate and final outcomes, and operational risks can be identified and managed. This is the key point of overlap with project management techniques, which could usefully be applied to the program logic matrix.

Every policy idea will contain multiple competing logic models - one that expresses the intended logic, that is, the course of events or chain of results anticipated and promised by the policy's supporters (some version of this becomes the official logic once a policy has been adopted), and another that describes the 
chain of results most likely to unfold if the policy were adopted and implemented, that is, the realistic logic. The realistic logic is, of course, the policy analyst's holy grail - a glimpse of the policy's actual future. If policy analysts could accurately describe the realistic logic before a policy is implemented, they could advise more confidently about both the preferred course of action for government to take and the best way to manage risks in chosen policies. ${ }^{2}$

Unfortunately, analysts cannot generate accurate, realistic logics with any confidence, at least not in complex policy areas, but they can test official logic against its opposition logic. Opposition logic refers to the chain of failures or disasters that would result if a policy fulfilled the expectations of its critics rather than its supporters. Comparing official and opposition logics yields considerable insights about a policy's risks - both political and operational. This technique allows policy analysts to make use of political rhetoric - the language of both clients and clients' opponents - to structure and guide (but not pre-empt) analysis. It also helps clarify the principle of the inseparability of policy ends and policy means by emphasising the importance of clarifying causal theory. Starting from identical programs, different causal theories can lead to entirely different outcomes, and for this reason, logic models need to explain why and how they expect one particular set of outputs to generate a particular set of outcomes.

Some policies will arrive on the analyst's desk already sporting multiple rationales thanks to coalition logic. Because officials can bargain around means more easily than around ends, they often find it easier to agree on a particular activity than to agree on a goal for the activity (Kingdon, 1984). For example, supporters of wetlands conservation might assemble a coalition consisting of environmentalist groups, who wish to protect fragile species, and traditional hunting clubs, who wish to preserve duck-breeding habitats so that they can hunt the ducks. Although the groups' values and purposes diverge rather sharply at the top of the policy's outcomes chain, they coincide lower down the chain, and this coincidence of intermediate outcomes may be sufficient to sustain the political coalition. In this example, the politically astute user of intervention logic may decide to obscure the divergence in ultimate ends by truncating the outcomes chain somewhere in the middle, below the point of disagreement.

One of the most forceful of all logic models is the analogy. Analogies may take normative forms, for example, work is to welfare receipt what voting is to citizenship. Or they may take hypothesis-like forms, for example, the decriminalisation of marijuana is to expected marijuana consumption what repeal of prohibition was to alcohol consumption in the U.S. in the 1930s (MacCoun and Reuter, 2001). The analogical device informs policy by revealing and providing evidence about the mechanisms that cause outcomes-evidence taken from analogous, but not identical, times, places or policy sectors. 
Intervention logic offers policy advisers a structured approach to critical thinking rather than a formula-driven decision tool. Whereas decision-based methods tell the advisor to recommend the option with the highest score on the top-weighted criterion or the highest benefit/cost ratio, intervention logic does not produce any recommendation at all. Instead, to borrow Sir Geoffrey Vickers' (1965: p. 40) term, intervention logic helps the analyst build and communicate an 'appreciation' of the policy's key features - facts, values, assumptions, mechanisms of intended cause and effect, and likely feedback effects. The practice of logic modelling seeks to promote a critical stance toward conventional wisdom but from an internal vantage point rather than a bird's eye view. Intervention logic assumes that, at least in some cases, a policy's key features, including both strengths and weaknesses, are easier to see at close range. It assumes that we often cannot judge the degree of divergence between intentions and reality until we truly grasp the intentions. Therefore, the skilled intervention logic user starts by taking conventional wisdom seriously (even when one thinks it is wrong), modelling the rationale behind a current or proposed policy, and then identifying its strong and weak links.

\section{Toward Better Practice}

Experience with applying intervention logic in the New Zealand public service has generated a few lessons about good and bad practice.

\section{Learning $v$ accountability}

A common complaint about logic modelling is its vulnerability to being captured by conventional thinking. Once a policy or program backbone has been created, it tends to look authoritative and people may think twice about questioning it. Over the last several years, as New Zealand departments prepared their department-wide 'outcomes hierarchies' or logic models to be included in Statements of Intent, some concerns have been expressed about the tendency for departments to simply use the logic model format to rationalise and justify their status quo policies and outputs, rather than using it to examine critically their mix of outputs. The litmus test of outcomes-based management, and logic modelling, when used as one of its tools, is whether or not it gives departments a platform from which to make changes in their output mixes to boost effectiveness. It is not yet clear that such changes are occurring as hoped.

Does this absence of discernible impacts mean that logic modelling is either a bad idea or hopelessly unrealistic or both? On one hand, a methodological purist would have to condemn the kind of retrofitting application of logic models that departments are suspected of using in New Zealand. Good practice in intervention logic clearly emphasises the absolute necessity of revealing assumptions and risks associated with each backbone and critiquing each step in the causal logic. It is not meant to be used for rationalising or shoring up either current policy 
or someone's favoured proposals for change. On the other hand, no one should be surprised when departments respond to an official request for performance-related information by defending their existing programs. When faced with official reporting requirements, no matter how non-threatening the language of the requirement, rational departmental officials will always use whatever tools are available to weave the most positive picture possible of their department's development. Officials know that all reporting can and will be used to construct a 'performance story' tied to their departments (Mayne 2004), and it is natural for them to want to control that story to the greatest extent possible. ${ }^{3}$ For this reason, central agencies probably ought to acknowledge quietly that some sugar-coating of departmental performance stories is tolerable, but only if robust procedures are in place for scrutinising these performance stories and asking the kinds of hard questions that will reveal areas of weakness. Parliamentary committees, auditor agencies, and other institutional actors will probably play big roles in this. It may be time for government to direct some of its attention away from making marginal improvements in departmental reporting and direct it toward building more effective scrutiny and feedback arrangements.

Gregory (2004) has argued that political imperatives will always swamp serious efforts by policy advisers to question the government's policy thinking. Therefore, according to his argument, expecting policy advisers to use logic modelling techniques even for internal policy advice may be unrealistic. Even if Gregory is overstating somewhat the obstacles to free and frank policy advice, it is probably hopelessly idealistic for us to expect departments to publish reports on their websites that contain logic models revealing their current program's deepest vulnerabilities, particularly if the department is still early in the process of addressing those vulnerabilities. Good practice in logic modelling, if it happens anywhere, is most likely to be found in policy and management teams that are working behind the scenes to improve program effectiveness.

Transparency and accountability are fundamental values in a democratic system, and therefore, central agencies must specify particular forms of reporting that will be uniform across agencies. But at the same time, the art of crafting an effective public sector reporting system requires a delicate balance between Parliament's and the public's need for detailed information for assessment, on one hand, and departments' needs for time and space to carefully analyse and sensibly address problems behind the scenes, on the other hand. Rather than requiring departments to report on current weak points and future risks, I wonder if it might not be better for central agencies to require retrospective reporting from each department about how it has identified and addressed weaknesses in the recent past and learned from them. Knowing that they will be held accountable for evidence of recent learning may encourage officials to look for genuine learning opportunities now and in the future. This sort of retrospective reporting of learning is surely not game-proof, but it may provide 
a stronger incentive for genuine risk assessment and change management than the more direct reporting requirements provide.

Central agencies in New Zealand (and those advising them, including the author) are learning from their own recent experiences with intervention logic. The guidance documents for agencies around Managing for Outcomes and preparation of Statements of Intent made sustained and explicit reference to intervention logic techniques in 2002, while the 2003 and later versions of these documents did not endorse any particular methods for articulating the rationales linking outputs to outcomes. The more vigorous promotion of intervention logic in previous guidance documents generated backlash among some officials who felt that they were being forced not only to learn a new technique at relatively short notice, but also having to apply it to the broadest possible canvas - a whole department. Although central agencies provided considerable support, the task was probably too much too soon, and there were probably too few positive, internal incentives for departments to really get stuck into the task rather than simply ticking the box.

In hindsight, it may have been better to allow the interest in and enthusiasm for logic modelling to spread at a more natural pace across public service agencies and departments in New Zealand, fuelled by word of mouth and evidence of effectiveness. In addition to being slow, this kind of dissemination is hard to control, of course, and difficult to harness for purposes of reporting and assessment. It surely would have generated a potpourri of practices, very little uniformity, and huge difficulties for anyone trying to compare the effects of logic modelling practices on different agencies. In this case, however, a natural proliferation of practices may have been just what was needed to generate innovation and change, particularly with respect to practical areas where logic models are only recently being applied - including policy design, public management, strategic planning, and project management.

\section{Outcomes always happen to someone outside government}

A mysterious and powerful force has often been observed in logic modelling exercises, drawing participants away from thinking about intermediate and final outcomes towards thinking about internal government processes, such as: have we followed procedures? are we setting up the right networks? are we on time and within budget? are the operations people doing what they are meant to be doing, according to the policy? is the minister happy? These are urgent internal matters, and the public management/project management matrix associated with a logic model is suited to addressing these, but they should not to be confused with intended outcomes themselves. Outcomes (intermediate or final) are the consequences of government activity, as experienced by something or someone outside government - such as health status, educational achievement, border security, sustainable fish stocks, and the like. They are not processes of 
government activity. Logic models should start by thinking about the chains of outcomes that a particular program or policy is meant to produce, before turning to questions of resource allocation, staffing, procedures, networks, and other essential ingredients for making the chain work.

\section{Where logic models leave off and systems models begin}

Department-wide logic models may quickly become unreadable if all logical steps are included for all core programs (not to mention assumptions and risks as well). These 'copulating spider' diagrams, as current State Services Commissioner, Mark Prebble, once described them, are a common pitfall of logic modelling practice. Not only are they hard to read, but they also tend to miss out on opportunities to cut to the chase. Some programs' and departments' causal theories can be summarised simply and elegantly in just a few basic propositions; using a logic model to make these more complicated than necessary is a poor use of time and resources. Logic models are most useful when a department or program group can use them to stay focused on a few vital outcomes and on key stages in the output-outcome conversion process. A good logic model should reveal these logical 'hinges' rather than obscuring them (Baehler 2003).

However, those who use logic models to portray policy intentions will often find themselves under pressure to include in their diagrams every possible feedback loop and causal variable that might influence the policy's effectiveness. This is where policy logic models begin to shade into systems models of the policy environment. The tendency to drift from one technique to the other is natural and not necessarily to be avoided, but at the same time, modellers should try to keep certain important distinctions between the two practices clear in their own minds. The two most important distinctions, in my opinion, are between intention and reality, and between a policy idea and the setting in which it is meant to function.

The world is obviously a very complex place. Much social and even economic behaviour is notoriously difficult to explain and predict. No one can be certain how events and developments will be influenced (if at all) by any single government intervention, much less a complex array of policies and programs. Public policy experts like to repeat the mantra that we are constantly besieged by 'wicked problems' that morph before our very eyes and cannot readily be defined let alone solved using standard analytical tools. Brave souls in the social science world are now exploring how insights from complexity theory can be applied to wicked problems to help us understand them. These truly are important developments and worthy of more attention.

At the same time, however, it is important to remember that the basic logic of most government interventions is relatively simple. Policy logic has to be simple and forceful because (1) politicians have to be able to explain policies to 
stakeholders and citizens in order to win their support, (2) government policy itself is a fairly blunt instrument and delicate operations involving complex interactions of multiple variables are generally the responsibility of frontline staff and implementers (the algorithms of judgment used by frontline staff are virtually impossible to incorporate into policy or to express in a policy logic), and (3) as implementation scholars discovered decades ago, the more moving parts a policy or program has, the more opportunities there are for things to go wrong. For all of these reasons, intervention logic seeks to keep the policy backbone model relatively simple and straightforward. Logic backbones are usually linear to reflect the linear nature of most policy arguments - for example, if we subsidise or otherwise facilitate $X$, people will consume more of it; if we regulate $\mathrm{Y}$, the harms associated with it will decrease; if we provide a new service $\mathrm{Z}$, the target population will be enabled to function more effectively. As described above, laying out the intended logic of these interventions allows us to test it against what we know about how the real world works. Intended policy logic and social/economic reality need to be closely related to each other, but they are not the same thing.

This is where systems models come in. ${ }^{4}$ They allow us to map what we know about how a relevant piece of the world works, such as economic development processes, or family formation processes, or cycles of environmental degradation and repair. When policy analysts and evaluators are testing the logical chain of impacts associated with a particular policy or program, they must draw upon knowledge of the many complex and often chaotic influences and drivers that characterise the actual world into which policies and programs interject their resources and rules. Systems models are simply tools for describing what we know about this complex reality. The relationship between logic models and systems models is therefore a reflection of the relationship between intention and actual effect. Logic models plug into a systems model at one or more points with the intention of showing how a policy is expected to break a problem circuit or create opportunities for new patterns of interaction to emerge. Logic models plug into a systems model by way of influencing the system's incentives, changing the resource mix, reshaping the rules and norms governing the system, or otherwise influencing actors' tastes, preferences, and choices. This is where the co-production relationship described earlier becomes essential. Policy designers need to understand the ways in which each particular area of policy depends upon group or individual cooperation and action in order to generate outcomes.

Excellent practice in logic modelling, therefore, requires at least some use of systems modelling to map the context for policy intervention. At a minimum, good practice in logic modelling requires that practitioners keep the distinctions between intention and reality, and between the policy idea and its setting, as clear as possible. Confusing or ignoring these distinctions may produce a model 
that neither communicates the policy's basic theory nor describes the policy setting adequately.

Where systems are concerned, model builders also should be in regular contact with the department's operational staff, most of whom interact daily with programs, clients, and their real-life settings. Based on these interactions, operational staff are continually forming and revising their own, often unconscious, models of how various components of a program, service, or policy influence client behaviour, nudge economic trends, shape international relations, or alter patterns of environmental change. Head-office staff cannot begin to understand policy logic, policy systems, or policy complexity without regularly consulting the front lines and comparing what they find there with what the original policymakers promised to deliver.

\section{Top down or bottom up?}

Logic models are most useful when one has a particular program or policy in mind, but they can be used to generate policy ideas if one has a set of high-level desired outcomes and a working knowledge of the systems model. This approach is sometimes called top-down logic modelling because it begins by mapping the chain of outcomes that are known to contribute to a chosen outcome, rather than starting with a selected policy or program. The process of mapping these outcome chains closely resembles the systems modelling process (I sometimes call it 'systems lite') because the intermediate outcomes are simply variables that contribute to the final result. The process of producing the map helps participants organise what they know about the outcome and the conditions that contribute to or detract from it, and sometimes leads to creative ideas for interventions as the chains move down the page.

I have not seen very many departments using top-down logic modelling, and it may be that systems thinking is more appropriate in the kinds of blue-skies policy advice and strategic planning settings where this technique is most likely to be needed.

\section{Too soon to tell ...}

The frontier for logic practices - their potential contribution to both vertical and horizontal integration of public sector work - has yet to be explored. Can policy models be devised that allow policy designers, implementation planners, project managers, strategists, evaluators, and even ministers all to see at a glance how their separate activities fit together into a coherent whole? If so, what would these models look like? How much detail would they contain? Would they be expandable and contractible, depending upon the desired application? Can website-writing software help us think about the shapes and functions of these sorts of models? One can imagine an entire department's website organised around the intervention logic for its core outputs. It would say: Click here for 
the strategic view and high-level outcomes, click here for the intermediate outcomes associated with output $\mathrm{X}$, click here for the research projects designed to test assumptions of this causal link, click here for the plan to manage the risks associated with these intermediate outcomes, click here for a list of partners need to co-produce this outcome, and so on.

\section{Conclusion}

It is still probably too early to reach any definitive conclusions about the effects of logic modelling practices on policy advice, public management, and good government in New Zealand, Australia, or anywhere else, partly because their recent association with performance-related reporting documents has triggered a bit of backlash against these methods. Despite these setbacks, various forms of logic modelling are likely to continue evolving (though probably with different names) so long as individual analysts and managers continue to find them useful. The same is likely to be true of recent good-practice developments in the same 'cohort,' such as managing for outcomes, systems-based evaluation, and project management. As public policy and management fashions move on to the next set of enthusiasms, now is a good time to pause and look the core messages that underpin logic modelling and related practices: the principle that means and ends and their linking theories cannot easily be separated, and the principle of citizen-government co-production of outcomes.

This chapter has argued that logic modelling practices, combined with systems modelling, can help policy, implementation, and evaluation professionals harness these core insights and put them to use both within their own professional realms and also as a bridging device across functional realms in the public sector. Even if logic models are not the best solution to any single challenge posed by the outcomes-based approach to public policy and management, logic modelling may be worth further attention due to its distinctive capacity for crossing functional boundaries and speaking a language that unites the notoriously fragmented areas of policy, management, implementation, evaluation, and even politics. As the practice develops, it is not inconceivable that logic models may provide a common platform from which policy designers, public managers, project managers, and evaluators, as well as politicians and citizens, may begin to develop a shared understanding of government policy - what it is trying to accomplish and how - and a vision of where they fit in the overall chain of effective co-production. By this train of logic, the multi-dimensional package of principles and methods known as intervention logic or program logic deserves continued attention and development wherever governments are seeking to work across functional areas, across departments, and with citizens to convert public resources into public goods. 
Improving Implementation

\section{References}

Arnold, R. Douglas 1990, The Logic of Congressional Action. New Haven, CT: Yale University Press.

Baehler, Karen 2003, 'Managing for Outcomes: Accountability and Thrust,' Australian Journal of Public Administration 62(4): 23-34.

Cato, Bertha, William Chen, \& Shannon Corbett-Perez 1998, 'Logic model: A tool for planning and evaluating health and recreation prevention projects,' Journal of Physical Education, Recreation \& Dance 69(8): 57-61.

Eoyang, Glenda 2004, 'Soft Systems Methodology'. W.K. Kellogg Foundation. Available on http://users.actrix.co.nz

Funnell, Sue 1997, 'Program logic: An adaptable tool for designing and evaluating programs,' Evaluation News and Comment, July, pp 5-17.

Gregory, Robert 2004, 'Political Life and Intervention Logic: Relearning Old Lessons?' International Public Management Journal 7(3): 299-315.

Gregory, Robert 1989, 'Political rationality or "incrementalism"? Charles E. Lindblom's enduring contribution to public policy making theory,' Policy and Politics 17(2): 139-153.

Harris, Bill and Bob Williams 2005, 'Systems Dynamics Methodologies'. W.K. Kellogg Foundation. Available on http://users.actrix.co.nz.

Kingdon, John W. 1984, Agendas, Alternatives, and Public Policies. Boston: Little Brown.

Maani, Kambiz E. and Robert Y. Cavana 2000, Systems Thinking and Modelling. Auckland: Prentice Hall.

MacCoun, Robert J. and Peter Reuter 2001, Drug War Heresies: Learning from Other Vices, Times, \& Places. New York: Cambridge University Press.

Mayne, John 2004, Reporting on Outcomes: Setting Performance Expectations and Telling Performance Stories, Canadian Journal of Program Evaluation 19(1): 31-60.

Patton, Michael Quinn 1997, Utilization-Focused Evaluation: The New Century Text, 3rd edition. Thousand Oaks, CA: Sage.

Saldanha, Cedric D. and John F. Whittle 1998, Using the Logical Framework for Sector Analysis and Project Design: A User's Guide. Asian Development Bank. Manila, Philippines.

Schick, Allen 2001, 'Reflections on the New Zealand Model,' based on a lecture to The Treasury, Wellington, August.

Steering Group 2002, 'Managing for outcomes: Guidance for departments,' Managing for Outcomes Roll-out 2003-04. The Treasury, State Services 
Commission, Department of Prime Minister and Cabinet, and Te Puni Kokiri. Wellington, New Zealand.

Vickers, Sir Geoffrey 1965, The Art of Judgment: A Study of Policy Making. London: Chapman and Hall.

Wildavsky, Aaron 1987, Speaking truth to power. New Brunswick, NJ: Transaction Books.

Williams, Bob 2005, 'Complex Adaptive Systems'. W.K. Kellogg Foundation. Available on http://users.actrix.co.nz

\section{ENDNOTES}

1 I am reminded of the old joke: How many social workers does it take to change a light bulb? Only one, but the light bulb really has to WANT to change.

2 Intervention logic shares features with many other approaches, such as scenario planning and decision trees, but should not be confused with either. Scenario planning (Schwartz, 1996) takes a very broad scope and seeks to anticipate major shifts in social, economic, environmental, etc. patterns. (Intervention logic is closer to providing a structured approach to Bardach's (2000: pp. 32-33) more modest 'scenario writing' process, which he offers as an informal antidote to 'excessive optimism' on the part of analysts.) Decision tree analysis (Kidd, 1991) resembles intervention logic insofar as it includes the probabilities of both chance events and particular types of outcomes along various trajectories in its model. It differs from intervention logic, however, in treating the nodes in the sequence as intermediate choices to be made rather than intermediate outcomes to be produced.

3 It is important to note that when departments emphasise strong points over the weak points in their performance stories, this does not necessarily mean that department officials aren't interested in, or aren't aware of, the weak links in their output-outcome theories (although that is possible, of course). It may mean simply that department officials prefer to address these weak links internally, before exposing them to intense public and parliamentary scrutiny.

4 Those interested in exploring policy applications of systems thinking should have a look at Maani and Cavana (2000), Eoyang (2004), Harris and Williams (2005), and Williams (2005). 